\title{
EMPIRICO-STATISTICAL METHODS FOR ANALYSIS OF NARRATIVE AND NUMERICAL SOURCES WITH APPLICATIONS TO THE PROBLEMS OF ANCIENT AND MEDIEVAL HISTORY AND CHRONOLOGY
}

\author{
Volume one: The Development of the Statistical Tools. ISBN 0-7923-2604-0 \\ ISBN 0-7923-2606-7 (Set of two volumes) \\ Kluwer Academic Publishers, 1994. \\ ANATOLY T. FOMENKO \\ Chair, Differential Geometry and Applications \\ Department of Mathematics and Mechanics \\ Moscow State University \\ 119899 Moscow, Russia. \\ anatoly@fomenko.mian.su
}

Volume two: The Analysis of Ancient and Medieval Records. ISBN 0-7923-2605-9

It is regretfully common that numerous historical events are falsely dated. For instance, statistical and astronomical analysis of Ptolemy's Almagest (in "Geometrical and Statistical Methods of Analysis of Ptolemy's Almagest," by A. T. Fomenko, V. V. Kalashnikov, G. V. Nosovski) proves that the date of the compiling the star catalogue in the Almagest belongs to the time interval 600-1300 A.D. This fact contradicts the standard date of the creation of the Almagest: 2nd century A.D. How is it possible?

Chronology is what tells us how much time has elapsed between historical events and the present time. To determine a real chronology one must be able to translate the data from ancient documents into the terminology and notion of modern time reckoning. Many historical conclusions and interpretations depend upon what dates we assign to the events in a given ancient document. This problem is very complicated.

The chronology of ancient and medieval history in its present form was created in a series of works during the 16th and 18th centuries, beginning with J. Scaliger (1540-1609), the "founder of modern chronological science," and D. Petavius (1583-1652). The series of these works, however, is not entirely complete, as the well-known chronologist E. Bickerman observes, "there is no adequate, full-scale treatment of ancient chronology."

The accepted traditional chronology of the ancient and medieval world rests on quite a snaky basis. Indeed, between different versions of dating such important events as the foundation of Rome, there exists 500 years long (standard) deviation (T. Mommsen).

Consequently, it is not surprising that certain skeptical minds have made dramatic conclusions from the above-mentioned difficulties: de Arcilla, Isaac Newton, J. Hardouin, R. Baldauf, E. Johnson, N. A. Morozov and others. Thus, as early as the 16 th century A.D., Professor of Salamanca University, de Arcilla, published two papers in which he stated that the whole history earlier than the 4th century A.D. had been falsified. Isaac Newton devoted many years to historical and chronological studies. He made up his own tables in accordance with a new chronological version. Some of the important events of Greek history were moved forward by Newton chronologically 300 years, and those of Egyptian history even 
1000 years. The first serious attempt to systematize the considerable critical material and to analyze historical paradoxes and duplicates from the standpoint of natural science was carried out in the fundamental work "Christ," by esteemed academician N. A. Morozov (1854-1946), who was not only a revolutionary and public figure, but also a remarkable scientist with encyclopedic knowledge, an expert in chemistry, physics, mathematics, and history.

Consider the three famous eclipses of Thucydides - 5th century B.C. ("History of the Peloponnesian War," Bks. ii, 27-28; iv, 51-52; vii, 18-19, 50), which can be dated using modern methods. There are only two exact astronomical solutions: the first solution is August 2, 1133 A.D., March 20, 1140 A.D., and August 28, 1151 A.D., whereas the second is August 22, 1039 A.D., April 9, 1046 A.D., and September 15, 1057 A.D. This example is not unique.

In order to overcome the difficulties in establishing accurate chronology, one must try to view the subject from a different vantage point and create an independent methodology which is not based upon subjective impressions. Only after this is done should one proceed to analyze chronology in its entirety. In our opinion, the most worthwhile approach uses statistical analysis of various numerical characteristics of historical texts. Some new methods were suggested by the author and his colleagues. These methods make no claim to universality. Moreover, the results obtained by means of each individual method cannot be taken as definitive. A reasonable criterion for the validity of our results is an agreement between the dates which are obtained by different methods.

About fifty years ago, N. A. Morozov found three pairs of ruling ancient dynasties for which the sequences of lengths (periods) of reign, represented visually on the time line, bore a striking resemblance to one another. He suggested that in each case the two dynasties were actually reflections of a single, real dynasty which "became multiplied" as a result of mistakenly dating the same events described in different texts. However, it is not enough to rely upon subjective impression. For this reason we set about creating a formal quantitative method for determining whether the two dynasties are a merely different manifestation of a single dynasty ("dependent dynasties") or are truly distinct ("independent dynasties") of one another. The application of this method to historical data traditionally believed to belong to earlier than the 13th century A.D., unexpectedly led to the discovery of pairs of dynasties regarded as independent in all the senses, but for which the special proximity coefficient is extremely small.

We had to put together as complete as possible a table of events in traditional chronology of the ancient and medieval history of Europe, the Mediterranean, Egypt, and the Middle East. To do this we combined the information from 15 chronological tables and 228 primary sources. Together, these chronicles describe practically all important events between 4000 B.C. and 1800 A.D. In this way we constructed a table, which we call Global Chronological Diagram (GCD). Our statistical methods for dating events and recognizing duplicates were applied to the large quantity of historical data in the GCD table. After performing a vast computer experiment involving the analysis of hundreds of texts, we unexpectedly discovered pairs of periods which in traditional history are assumed to be independent (in all senses of the word), but have statistical characteristics which are extremely close.

Let us give an example. The chapter-volume graph for the primary sources which describe ancient Roman history from 753 B.C. to 236 B.C. has its local maxima at essentially "the same points" as the analogous graph for medieval Roman history from 300 A.D. to 816 A.D. Of course, here we must first align the two 500-year time intervals. This same statistical parallelism was also revealed by other methods.

The global chronological diagram represents the modern version of traditional "textbook" of ancient and medieval history and chronology (based on Scaliger's chronology). We investigate the inner hidden structure of this "textbook." Our calculations show that the "modern textbook" contains an extremely interesting system of statistical duplicates.

Speaking loosely, we might say that the commonly accepted "textbook" of ancient and medieval 
European, Mediterranean, Egyptian, and Middle Eastern history is a layered chronicle obtained by gluing together four nearly-identical copies of a shorter chronicle ' $\mathrm{A}$ '. The chronicle-original ' $\mathrm{A}$ ' describes the events from 9th century A.D. to 17th century A.D. The other three chronicles are obtained from 'A' by redating and renaming the events described in them; we rigidly move ' $\mathrm{A}$ ' in its entirety backwards in time by 333, 1053 and 1778 years (approximately). Thus, the "textbook" was obtained (many years ago) by duplication of its smaller part, namely - from chronicle 'A'. Almost all of the information in the original chronicle ' $A$ ' is concentrated to the right of 960 A.D. In reality, we have extensive historical records only starting from 960 A.D. Thus, the currently accepted global chronology before the 13th century A.D. is in need of radical changes. Conjecture: we have to redate a certain number of ancient events which until now have been placed in very ancient times. To do this we must take out large parts from the "textbook" (namely, the part before 10th century A.D.) and move them forward in time, as indicated above. After this procedure, one finds that the known written history of Europe, the Mediterranean, etc. becomes much shorter: most of the events which are traditionally dated earlier that the 10th century A.D. (ancient Rome, ancient Greece, etc.) turn out to be in the time interval from 10th century A.D. to 17th century A.D. Revising chronology in this way, one finds that many of the old paradoxes in traditional dating disappear.

However, we categorically disagree with the suggestion of N. A. Morozov and some of his predecessors that our information about antiquity is a fabrication (some fantasy) of later chroniclers. The results obtained by means of the new statistical dating methods show that almost all surviving ancient documents are authentic and written to the purpose of perpetuating real events rather than leading the future historians astray. More than that, many of the documents regarded today as adulterated turn out to be originals which are extremely and naturally consistent with our new version of short statistical chronology. In our opinion, practically everything described in the old documents "did, in fact occur." The problem is: when and where?

SUMMARY. These two volumes represent a major, unique work which is the first of its kind published in the English language. A comprehensive set of new statistical techniques is pre-sented for the analysis of historical and chronological data. These techniques constitute a new important trend in applied statistics.

The first volume concentrates mainly on the development of statistical tools and their applications to astronomical data: of ancient eclipses, of the Almagest, etc. The second volume analyzes ancient and medieval chronicles and records (Egyptian, Byzantine, Roman, Greek, Babylonian, and European). An astonishing wealth of historical data is presented. The surprising conclusions are drawn from the new approach to the historical chronology designed in an entirely different time scale. [The conventional chronology can be restored from the one proposed by Fomenko by using special "time shifts."] They will certainly provoke controversy and serious debates. In particular, in this scenario, ancient Rome and Greece are placed in medieval times. The book provides all necessary backgrounds and materials for intelligent participation in such debates.

Audience: Statisticians, historians, astronomers, archaeologists, and others with an interest in the integrity of the historical data with the use of modern science.

\section{CONTENTS}

VOLUME I

(Excerpts)

Foreword (by Albert N. Shiryaev)

Preface.

\section{Chapter 1. PROBLEMS OF ANCIENT AND MEDIEVAL CHRONOLOGY.}

1. The Global Chronological Diagram of ancient and medieval history. 
1.1. Moon's elongation and R. Newton's conjecture.

1.2. The Dark Ages and Renaissance epochs.

1.3. How to substantiate ancient chronology.

1.4. Statistical methods: new possibilities.

1.5. Duplication effect in ancient history and chronology.

1.6. Global Chronological Diagram and "Modern Textbook" of ancient and medieval history.

1.7. The "Modern Textbook" is composed from four identical pieces.

1.8. Certain corollaries and interpretations.

1.9. What's to be done with Moon's elongation?

2. Computation of second derivative of Moon's elongation and statistical regularities in distribution of certain astronomical data.

2.1. Parameter D and R. NEWTON's paper "Astronomical evidence concerning non-gravitational forces in the Earth-Moon system".

2.2. Available observations of ancient solar and lunar eclipses.

2.3. Method of formal astronomical dating.

2.4. Effect of shifting the eclipse dates upwards.

2.5. Example: three famous eclipses of Thucydides.

2.6. Example: eclipse described by Livy.

2.7. Example: eclipse described by Livy and Plutarch.

2.8. Example: evangelic eclipse described in the New Testament and connected with the Crucifixion.

2.9. New graph of $D^{\prime \prime}$ oscillates about one and the same value. No non-gravitational theories are necessary.

2.10. Three rigid "astronomical shifts" of ancient eclipses.

2.11. Complete picture of astronomical shifting.

2.12. Coincidence of the astronomical shifts with the three basic chronological shifts on the Global Chronological Diagram.

3. Traditional chronology of the flares of stars and the dating of ancient horoscopes.

3.1. Ancient and medieval flares of stars. Famous Bethlehem star.

3.2. Astronomical dating of ancient Egyptian horoscopes.

3.3. Astronomical dating of the horoscope described in the Book of Revelation.

\section{Chapter 2. NEW STATISTICAL METHODS FOR DATING.}

4. Certain statistical regularities of information density distribution in texts with scale.

4.1. Text with scale. General notion.

4.2. Information characteristics ( = informative functions) of a historical text. Volume function, name function, reference function.

4.3. Theoretical model describing the distribution of local maxima for the volume function of a historical text. Primary stock. Information density conservation law.

4.4. Correlation of local maxima for the volume graphs of dependent historical chronicles. Surviving stock graph.

4.5. Mathematical formalization. Numerical coefficient $d(X, Y)$ which measures "the distance" between two historical texts $\mathrm{X}$ and $\mathrm{Y}$.

4.6. Mathematical formulas for computing $d(X, Y)$. Mathematical corrections of maxima correlation principle. 
4.7. Verification of maxima correlation principle against a concrete historical material.

4.8. New method for dating historical events.

4.9. Discovery of dependent (parallel) historical epochs traditionally regarded as different.

4.10. Dynasty of rulers and durations of kings' rule as important informative function.

4.11. Frequency distribution of those kings' rules who lived in 1,400 - 1,800 A.D. and in 3,000 B.C. - 1,800 A.D.

4.12. Concept of statistical parallel historical texts and epochs.

4.13. "Written biography" or enqu^ete-sode of a historical character.

4.14. Method of comparing the sets of informative functions for two historical epochs.

4.15. Computational experiment.

4.16. Remarkable decomposition of the Global Chronological Diagram into the sum of four practically indistinguishable chronicles.

5. Method of duplicate recognition and some applications to chronology of ancient dynasties.

5.1. Process of measuring random variables.

5.2. Distance between two random vectors.

5.3. Dynasty of rulers. Authentic dynasty and numerical dynasty. Dependent and independent numerical dynasties. Small distortion principle.

5.4. Basic errors leading to controversy among chroniclers as to the duration of kings' rule.

5.5. Experimental frequency histogram for kings' rule duration.

5.6. Virtual dynasties and mathematical model for an errors of the chronicler made in measuring of the rule duration.

5.7. Small distortion principle and computer experiment.

5.8. Pairs of dependent historical dynasties earlier regarded as independent.

5.9. Distribution of dependent dynasties in the "Modern Textbook of Ancient History".

5.10. Dependent dynasties in the Bible and parallel with the European history.

6. New empirico-statistical procedure for historical text ordering and its application to problem of dating.

6.1. Chapter-generation.

6.2. Frequency damping principle.

6.3. Method of finding the chronologically correct order of chapters in a historical chronicle.

6.4. Frequency duplicating principle and method of duplicate recognition.

6.5. Distribution of old and new duplicates in the Old and New Testament. Striking example: the Revelation of John.

6.6. Epochs-duplicates in the "Modern Textbook of Ancient History".

Chapter 3. NEW EXPERIMENTAL AND STATISTICAL METHODS FOR DATING ANCIENT HISTORY EVENTS AND APPLICATION TO GLOBAL ANCIENT WORLD AND MEDIEVAL CHRONOLOGY.

7. Introduction. N.A. Morozov and modern results.

7.1. Introduction. N.A. MOROZOV and modern results.

8. Problems of historical chronology. 
8.1. Roman chronology as the "spinal column" of European chronology.

8.2. J. Scaliger, D. Petavius, Christian chronographers and secular chronography.

8.3. Questioning the authenticity of Roman tradition. Hypercriticism and T. Mommsen.

8.4. Difficulties accompanied the establishment of Egyptian chronology.

8.5. Competing chronological versions. De Arcilla, J. Hardouin, I. Newton and R. Baldauf.

8.6. Tacitus and Bracciolioni. Cicero and Barzizza.

8.7. Vitruvius and L. Alberti.

8.8. "Chaos of medieval dating" (E. Bickerman). Medieval anachronisms and medieval ideas of time.

8.9. Chronology of the biblical manuscripts. L. Tischendorf.

8.10. Vowels of ancient manuscripts.

8.11. Traditional biblical geography.

8.12. Problems of geographical localization of ancient events.

8.13. Modern analysis of biblical geography.

8.14. Ancient originals and medieval duplicates. Anachronisms as a common feature in the medieval chronicles.

8.15. Names and nicknames. Hand-written books.

9. Astronomical and mathematical analysis of the Almagest.

9.1. Morozov's analysis of the first medieval editions of the Almagest.

9.2. On the statistical characteristics of the Almagest. Star catalogue structure.

9.3. Accuracy of the Almagest star coordinates.

9.4. Problem of dating the Almagest from the individual stars' proper motion.

9.5. Halley's discovery of stars' proper motion and the Almagest.

10. Archaeological dating methods.

10.1. Classical excavation methods.

10.2. Numismatics.

10.3. Dendrochronology method.

10.4. Radiocarbon method.

11. Astronomical dating. Ancient eclipses and horoscopes.

12. New experimental and statistical methods of dating ancient events.

12.1. Introduction.

12.2. Volume graphs for historical chronicles. Maximum correlation principle. Computational experiment and typical examples.

12.3. Method of recognition and dating ancient rulers' dynasties. Small distortion principle.

12.4. Frequency damping principle. The method of ordering historical texts in time.

12.5. Applications to the Roman and Greek history.

12.6. Frequency duplication principle. Duplicate discovery method.

12.7. Statistical analysis of the complete list of all the names mentioned in the Bible.

12.8. Statistical analysis of the complete list of all parallel passages in the Bible.

12 9. Duplicates in the Bible.

12.10. The enqu^ete-code or formalized "biography" method.

12.11. A method for the chronological ordering of ancient maps.

13. Construction of the Global Chronological Diagram and certain results of dating methods application to ancient history.

13.1. Ancient and medieval history "textbook".

13.2. Duplicates.

13.3. Dependent dynasties. 
13.4. Agreement of different methods.

13.5. Three basic chronological shifts.

13.6. Biblical history and European history.

a. Volume graphs for the Old Testament and "European textbook" from 850 B.C. to 1400 A.D.

b. The overlap of some biblical and European events.

Babylonian captivity and Avignon exile.

13.7. The beginning of "authentic" history in the 10th century A.D.

13.8. The chronological version of Morozov and the author's conception.

13.9. The confusion between the two Romes, viz., in Italy and the Bosphorus (New Rome).

13.10. A universal mechanism which could lead to the chroniclers' chronological errors.

13.11. J. SCALIGER, D. PETAVIUS and the famous Council of Trent. Creation of traditional chronology.

14. The "dark ages" in medieval history.

14.1. Medieval Italy and Rome.

14.2. Medieval Greece and Athens.

14.3. History of religions.

14.4. Indian history and chronology.

\section{VOLUME II}

Introduction.

Chapter 1. METHODS FOR THE STATISTICAL ANALYSIS OF NARRATIVE TEXTS.

1. Maximum correlation principle for historical chronicles and its verification by distribution functions. Analysis of Russian chronicles.

2. Maximum correlation principle and its verification by frequency histograms. Method for discovery of dependent historical texts. Period of "confusion" in the history of Russia (1584-1600 A.D.).

3. Method for dating events of history, described in chronological texts, and its verification against reliable historical data.

4. Methods for ordering and dating old geographic maps and descriptions.

4.1. Map-code and map-improvement principle.

4.2. Confirmation of the map-improvement principle.

4.3. Herodotus' map.

4.4. Medieval geography.

5. Frequency distribution in numerical ruler's dynasties.

5.1. Parallel ruler's dynasties.

5.2. Statistical parallel between Carolingians and 3rd Roman Empire.

5.3. Statistical parallel between Holy Roman Empire and 3rd Roman Empire.

5.4. Statistical parallel between Holy Roman Empire and Empire of the Habsburgs.

5.5. Statistical parallel between Holy Roman Empire and 2nd Roman Empire.

5.6. Statistical parallel between Holy Roman Empire and Kingdom of Judah.

5.7. Statistical parallel between Roman coronations of Holy Roman emperors and Kingdom of Israel.

5.8. Statistical parallel between 1st Roman pontificate and 2nd Roman pontificate.

5.9. Statistical parallel between 1st Roman Empire (Regal Rome) and 3rd Roman 
Empire.

5.10. Statistical parallel between 2nd Roman Empire and 3rd Roman Empire.

5.11. Statistical parallel between Kingdom of Judah and Eastern Roman Empire.

5.12. Statistical parallel between Kingdom of Israel and 3rd Roman Empire.

5.13. Statistical parallel between 1st Byzantine Empire and 2nd Byzantine Empire.

5.14. Statistical parallel between 2nd Byzantine Empire and 3rd Byzantine Empire.

5.15. Statistical parallel between medieval Greece and ancient Greece.

5.16. Statistical duplicates of Trojan war.

5.17. "Modern textbook of European history" and its decomposition into the sum of four shirt isomorphic chronicles.

5.18. Possible explanation of the three chronological shifts discovered in the Global Chronological Diagram.

1. General idea and 1,000-year shift.

2. 333-year shift.

3. 1,800-year shift.

5.19. Dionysius the Little.

6. Some other independent proofs of existence of three basic GCD chronological shifts.

6.1. The Roman popes' list as the spinal column of medieval Roman history.

6.2. Mean age of all old historical names and the frequency damping principle for the matrix columns.

6.3. Biblical name square matrix and statistical duplicates in the Old and New Testament.

6.4. Matrix of parallel passages in the Old and New Testament.

6.5. Related name scattering in chronological lists. Relation matrix.

1. Introduction.

2. Name list of secular or church rulers.

3. Correct and incorrect chronology in the name list. Frequency histograms.

4. Computation of histograms for real historical texts.

5. Histograms related to the Roman popes' name and nationality lists.

6. Damping succession in a historical chronicle.

7. Results related to the lists of the biblical names and parallel passages.

8. Chronological shifts between the duplicates in chronologically incorrect chronicle.

9. The card deck problem and chronology.

10. Relation matrix: preliminaries.

11. Principal definitions. Assumptions about the structure of the correct chronological text.

12. Relation measure. Problem of separation of large and small relations in chronicle.

13. Frequency histograms for relation appearance. Choice of thresholds.

14. Results related to the Roman popes' name list. Chronological shifts.

15. The list of Roman emperors' names and the related chronological shifts.

16. The comparison of the obtained results with the Global Chronological Diagram decomposition. 
Chapter 2. ENQU^ETE-CODES OF CHRONOLOGICAL DUPLICATES AND BIOGRAPHICAL PARALLELS. THREE CHRONOLOGICAL SHIFTS: BYZANTINE-ROMAN 333-YEAR SHIFT, ROMAN 1,053-YEAR SHIFT AND GRECO-BIBLICAL 1,800-YEAR SHIFT.

1. Frequency characteristics and enqu^ete-codes of historical periods in 82 B.C. -217 A.D. (2nd Roman Empire) and 300 - 550 A.D. (3rd Roman Empire). First basic 330-year rigid shift in the Roman history.

1.1. Ancient sources and their origin. Tacitus and Bracciolini.

1.2. Complete list of Roman emperors in 2nd Roman Empire and 3rd Roman Empire.

1.3. 330-year rigid shift in the Roman history. Parallel between 2nd Roman Empire and 3rd Roman Empire. Remarkable biographical parallel.

2. Charlemagne's Empire and Byzantine Empire. 330-year rigid shift. Comparison of the 4-6th cc. A.D. and 7-9th cc. A.D.

3. Chronological "cut" in the traditional version of ancient history.

4. Second basic 1,053-year chronological shift in the European history.

4.1. General structure of second 1,053-year chronological shift and third 1,800-year chronological shift.

4.2. Parallel between 1st Roman Empire (Regal Rome), 3rd Roman Empire and the Bible.

4.3. Tarquins war and Gothic war. 1,053-year chronological shift and the formula $\mathrm{X}+300$. Comparison of the historical events in the 6th c. B.C. and 6th c. A.D.

1. War prehistory.

2. Start of GTR-war.

3. War with Rome.

4. Stream of parallel events.

5. End of GTR-war.

4.4. 2nd Roman Empire and Holy Roman Empire in 10-13th cc. A.D. 1,053-year chronological shift and the formula $\mathrm{X}+300$.

1. Ancient Rome and medieval Rome in 555-850 A.D.

2. John the Baptist and John Crescentius (10th c. A.D.).

3. Jesus Christ and Gregory VII Gildebrand (11th c. A.D.).

4. Star flares in 2nd Roman Empire and Holy Roman Empire. "Evangelical star" in A.D.1.

5. Eclipse that occurred during the Crucifiction.

4.5. 3rd Roman Empire and Holy Roman Empire. 720-year chronological shift as the difference between 1st and 2nd basic chronological shifts. Trojan war, Gothic war and Italian war in the 13th c.A.D.

5. Parallel between Western 3rd Roman Empire and Biblical Kings of Israel.

Enqu^ete-codes of historical periods 9-5th cc. B.C. and 3rd-6th cc. A.D.

5.1. Complete table of both streams.

5.2. Remarkable biographical parallel.

6. Parallel between Eastern 3rd Roman Empire and Biblical Kingdom of Judah.

6.1. Complete table of both streams.

6.2. Remarkable biographic parallel.

7. The medieval Song of Roland and the ancient biblical Book of Joshua.

7.1. History of the poem Song of Roland.

7.2. Parallel between medieval poem and ancient chronicle. Table of the isomorphism. 
8. Third basic 1,800-year rigid shift in ancient chronology. Famous GTR-war and its chronological duplicates in different epochs of traditional history.

8.1. Trojan war and Gothic-Tarquinian war.

1. Medieval Trojan cycle. Homer, Dares and Dictys.

2. Rough comparison.

3. "Legend of a woman" and start of war.

4. Naples' and Troy's falls.

5. Greek Trojan horse and Latin Naples aqueduct.

6. Achilles, Patroclus and Valerius Brutus.

7. Achilles, Hector and Belisarius, Vitiges.

8. Achilles' "betrayal" and Belisarius' "betrayal".

9. Troiles-Totila; Paris-Porsena.

10. The other Trojan legends.

11. Medieval anachronisms in ancient Trojan cycle.

12. The Christian dating of the Trojan war.

8.2. Trojan war and GTR-war in the 1st c. B.C. (Sulla, Pompey and Julius Caesar).

1. New parallels in Roman history (the "great Triumvirate": Sulla, Pompey, Julius Caesar and GTR-war in the 6th c. A.D.).

2. Four statistical duplicates: Gothic war in 6th c. A.D., Roman war (Julius Caesar) in 1st c. B.C., Trojan war and Tarquins' war.

3. "Principal king".

4. "Legend of a woman".

5. Marcius Junius Brutus and Patroclus.

6. Vercingetorix and Hector.

7. Julius Caesar and Achilles.

8. Anthony and Antonina.

8.3. The GTR-war of the 6th c. A.D. and "Nicae's" mutiny.

9. Egyptian chronology.

9.1. Difficulties in creating Egyptian chronology.

9.2. Astronomical dating of the Zodiacs in the temple in Dandarach.

1. "Round Zodiac" and its horoscope. History of the problem.

2. Decoding of the "round" Zodiac by comparing with medieval astrographic charts.

10. Some strange features of the Ptolemy's Almagest. Preliminary remarks.

10.1. Latin and Greek editions.

10.2. A. Durer's astrographic charts in the first editions of the Almagest.

11. Duplicates in Greek chronology. 1,800-year chronological shift.

11.1. Epoch of Crusades in 1099-1230 A.D. and epoch of great Greek colonization in 8-6th cc. B.C.

11.2. Charles of Anjou and Cyrus.

11.3. Matilda and Miltiades.

11.4. Greco-Persian war and the battle of 300 Spartans with Xerxes' armies at Thermopylae.

11.5. War in medieval Greece and Peloponnesian war in ancient Greece.

11.6. Medieval Mahometans and ancient Macedonians. Mahomet II and Philip II. 


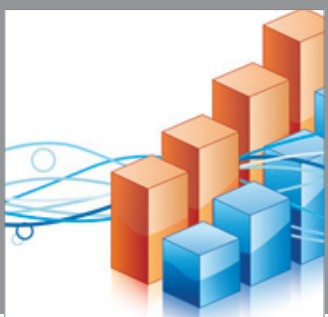

Advances in

Operations Research

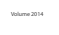

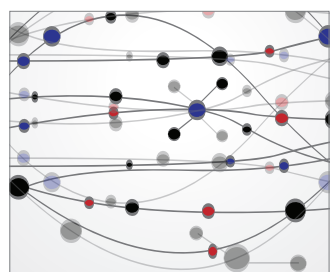

\section{The Scientific} World Journal
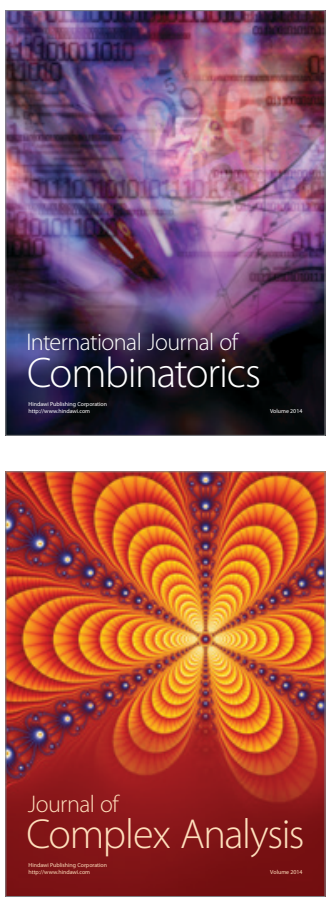

International Journal of

Mathematics and

Mathematical

Sciences
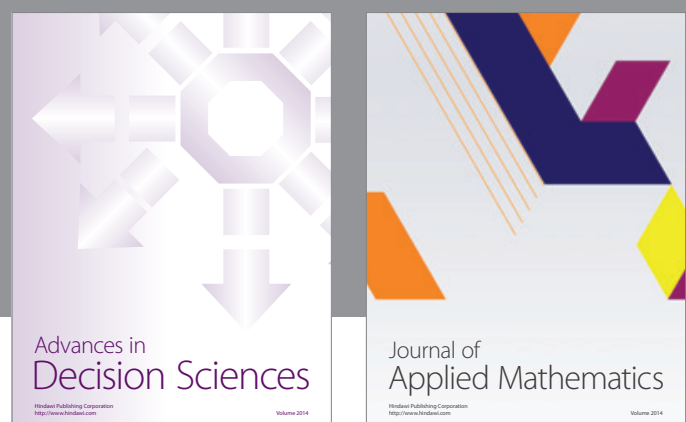

Journal of

Applied Mathematics
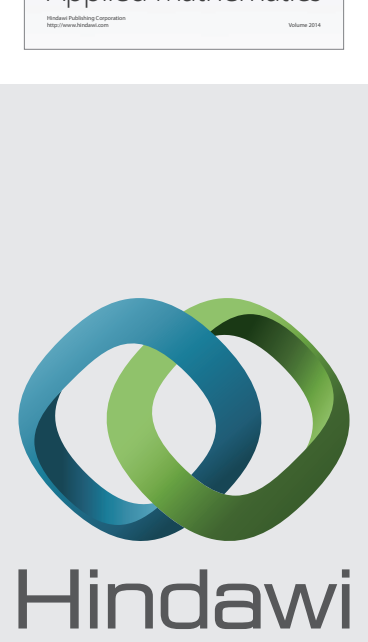

Submit your manuscripts at http://www.hindawi.com
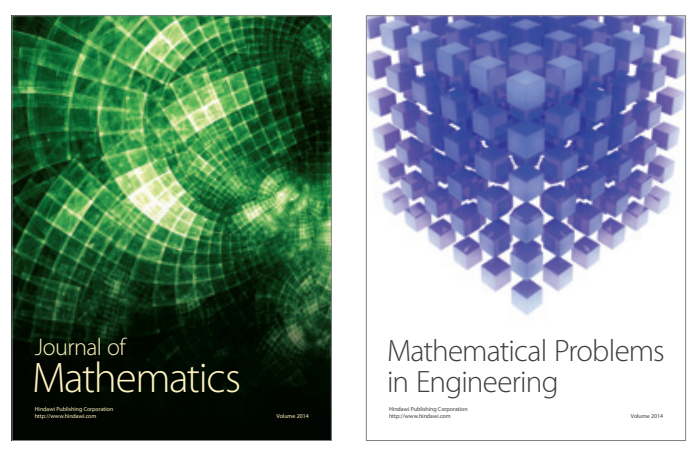

Mathematical Problems in Engineering
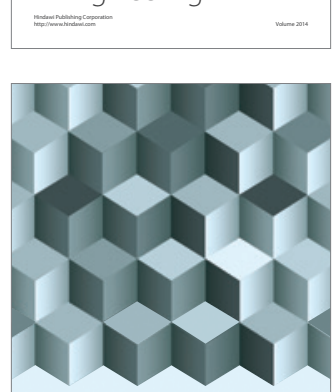

Journal of

Function Spaces
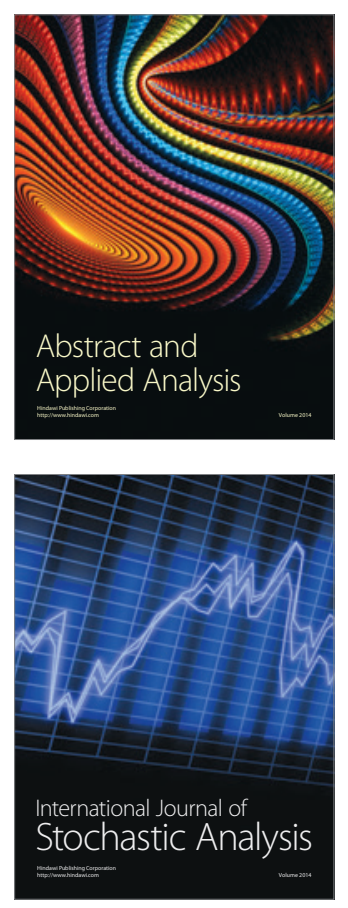

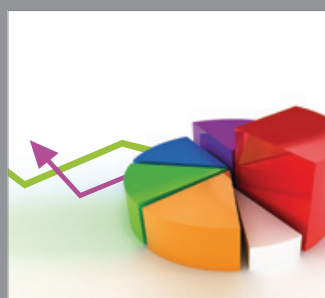

ournal of

Probability and Statistics

Promensencen
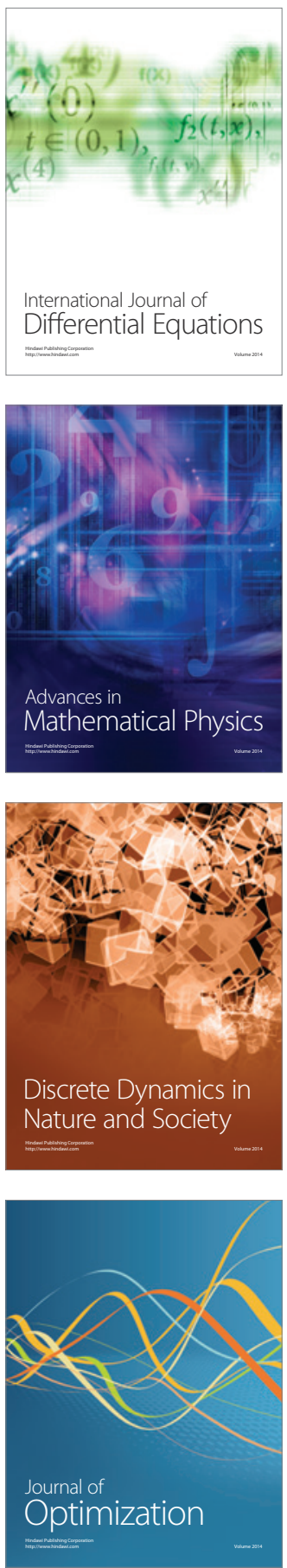